\title{
La configuración del espacio público en el primer peronismo
}

The configuration of the public space in the first peronism

\author{
Marilina del Valle Truccone mari_truccone@hotmail.com \\ http://orcid.org/0000-0001-6199-1002 \\ Centro de Investigaciones y Estudios sobre Cultura y Sociedad; \\ Universidad Nacional de Córdoba (Argentina)
}

\section{Resumen}

El presente artículo tiene como objetivo visibilizar las tensiones que atraviesa a lo público como un espacio intermedio, entre el Estado y la sociedad civil, desde una mirada discursiva de lo social. La constitución del espacio público implica la condición de posibilidad de nuevas inscripciones subjetivas, por lo que es considerado como un escenario de significación social. En este sentido, se realiza un análisis sobre la escritura de cartas a figuras estatales como Juan y Eva Perón, en relación a la emergencia de nuevas subjetividades en el marco de una reconfiguración de lo público. Por lo tanto, las identificaciones suscitadas entre diferentes 
sectores ciudadanos y el discurso político peronista se establecen en un espacio donde se define lo que significa una comunidad y los límites que estructuran su interior y su exterior.

Palabras clave: Peronismo; espacio público; ciudadanía.

\begin{abstract}
The objective of this article is tomake visible the tensions that go throught the public as an intermédiate space, between the State and civil society, from a discursive view of the social. The constitution of the public space implies the condition of possibility of new subjective inscriptions, that is why it is considered like a scene of social significance. In this sense, an analysisis made on th ewriting of letters to state figures such as Juan and Eva Perón, in relation to the emergence of new subjectivities with in the frame work of a reconfiguration of the public.Therefore, the identifications raised between different citizen sectors and the Peronist political discourse are established in a space that defines what a community means and the limits that structureits interior and exterior.
\end{abstract}

Keywords: Peronism; publicspace; citizenship.

La experiencia política del peronismo implicó una serie de transformaciones en las relaciones sociales y en la configuración del orden social, en tanto supuso la recomposición de excluidos del sistema socio-productivo a la escena política. En este sentido, en el presente trabajo nos motiva problematizar la configuración que adquirió el espacio público durante el primer peronismo. En esto, afirmamos que el estudio del espacio público implicó, en general, una disyuntiva entre la diferenciación de un espacio burocrático-administrativo dominado por la estatalidad; y por otro lado, como un espacio autónomo que somete a control al poder estatal, bajo un proceso de racionalización (Retamozo, 2006).

En contraposición a estas lecturas, retomamos el espacio público como la condición de posibilidad de nuevas inscripciones subjetivas en un determinado orden social, para pensarlo como un escenario de significación precario e históricamente cambiante. De esta manera, sugerimos que el espacio público se conforma como el momento en que se despliega el carácter dinámico e inestable de las relaciones y de las significaciones sociales; estimando que es allí donde la politicidad que constituye a lo social se expresa con particular intensidad. De este modo, el presente trabajo viene a poner en discusión las contradicciones, tensiones y 
límites que demarcan a lo público. Específicamente, en primer lugar nos proponemos investigar acerca de la relación entre espacio público y primer peronismo; en segundo lugar, intentaremos analizar la constitución del espacio público como un escenario de identificación subjetiva; y por último, planteamos indagar las intervenciones que sobre dicho espacio ejercieron los sujetos trabajadores, en su vínculo con la experiencia política del peronismo. Para ello, tomaremos un acervo documental específico: las cartas enviadas a Juan y Eva Perón, disponibles en el Archivo General de la Nación (AGN) (1).

\section{El espacio público y el primer peronismo}

Los estudios sobre el espacio público y el primer peronismo se han enfocado en modos diversos de establecer la relación entre ambas categorías. Por ello, el análisis sobre la delimitación de un nuevo espacio público se encuentran en trabajos que hacen referencia sobre intervenciones públicas, tales como movilizaciones, actividades recreativas y festivas; como también en el carácter novedoso que el peronismo implicó en términos de la construcción de un nuevo espacio simbólico (2). Específicamente, en nuestro trabajo asociamos la reconfiguración de lo que significó lo público con las dinámicas socio-políticas de la experiencia política peronista (Acha, 2016).

En este sentido, el trabajo de Plotkin (1994) retoma el despliegue de los mecanismos simbólicos e institucionales del Estado. El autor reconoce que el peronismo dejó un legado que se interpreta como la reformulación de las relaciones entre el Estado y la sociedad; y a su vez, la redefinición identitaria de diversos sectores de la sociedad argentina. En este sentido, la fortaleza del estudio de Plotkin reside en explicar el carácter rupturista que significó el peronismo, que no puede ser explicitado solamente en las mejoras en las condiciones de vida. Por lo tanto, el autor afirma que el Estado tomó el rol de árbitro final y absoluto en los conflictos políticos y sociales. En esto, la apariencia de unidad y consenso fue expresada en mitos y símbolos, monopolizando en esa operación el espacio público simbólico y deslegitimando la articulación de un sistema simbólico alternativo. De esta manera, el estudio de Plotkin permite pensar que el peronismo redefinió de manera decisiva las relaciones entre el Estado y la sociedad, a partir de la conformación de un espacio público como un nuevo espacio de significación de los sujetos y sus prácticas. Suponiendo estas consideraciones un excesivo énfasis en la figura del Estado, entendido como un actor plenamente centralizador y jerárquico. En este marco, adquiere relevancia traer a colación los supuestos de la peronización del espacio público de Castillo (2012). En su trabajo sobre el peronismo en la ciudad de Jujuy, se 
sugiere que la redefinición del espacio público se dio a partir de la reestructuración de las relaciones sociales, como efecto de la partición del espacio social entre sectores trabajadores peronistas y la oligarquía azucarera. Una cuestión interesante de destacar, es la reconfiguración de la trama urbana, como parte de la vocación transformadora del peronismo. En este sentido, la peronización del espacio público fue la expresión de la transformación que significó el régimen, que iban desde una redefinición arquitectónica, hasta las expresiones de fervor hacia el peronismo en la calle, en actos y movilizaciones. En su trayecto, Castillo da por sentado que la peronización del espacio público fue en detrimento del carácter dialógico del mismo, como efecto de la limitación de la participación política a sectores antiperonistas. Por ello, este proceso tuvo que ver con la constante recuperación de la simbología peronista y de sus líderes en aspectos cotidianos.

Ahora bien, en ambas lecturas advertimos que el estudio sobre el espacio público se encuentra dominado por un análisis de la creación de una simbología y ritual peronistas, sin tener en cuenta la recuperación y usos que de esos símbolos, los sujetos hicieron para sí. Es decir, que la reconfiguración del espacio público se evidenció, para el autor, como una operación desde arriba, al sostener el argumento de la característica autoritaria del populismo y la pasividad a la que los sujetos se relegaron.

Hasta aquí, podemos avizorar la importancia que tuvo la experiencia peronista en términos de la redefinición del espacio público, como también sobre la discusión acerca de los alcances del Estado. Sin embargo, en los trabajos mencionados distinguimos una tendencia a suponer un proceso unívoco de homogeneización social, direccionado desde el Estado hacia los sujetos. De este modo, como señala Acha (2016), la definición sobre lo público durante los años peronistas, implicó una exagerada prevalencia a Perón y al Estado. Por lo que, según el autor, se avala una lectura unidimensional, unidireccional y monoespacial de la experiencia peronista, en relación a la constitución de su relación con sectores mayoritarios de la sociedad argentina. Estas mismas apreciaciones encuentran su correlato en los estudios acerca de la expansión de la ciudadanía, por los cuales se describe de qué manera sectores de la sociedad accedieron a diferentes formas de bienestar social, en relación a un Estado activo frente a sujetos pasivos (Torre y Pastoriza, 2004).

El énfasis que realizan los autores mencionados al respecto del despliegue estatal, obtura la mirada para analizar la compleja interrelación entre los procesos políticos simbólicos y su recepción o dimensión subjetiva. Entonces, abrevamos en una dificultad para avanzar de manera más precisa y en mayor profundidad sobre la recepción del discurso peronista, en relación a la proliferación de iniciativas y actividades de los sectores trabajadores. El trabajo de Acha (2004) resulta sugerente para complejizar en cierta manera esta cuestión. A contramano 
de las lecturas que sobrecargan al Estado peronista de un protagonismo fundamental, Acha contribuye a pensar la emergencia del peronismo como la activación de una sociedad política que partía de demandas desde la sociedad civil; en vistas de subvertir el orden sociedadEstado. Al establecerse una sociedad política peronista, se reconoce la interrelación entre sujetos y el Estado, en tanto se admite una reconfiguración de sus alcances en el escenario político, a partir de una porosidad entre la esfera tanto civil como estatal e inaugurando el carácter político de las redes creadas durante el peronismo. De ahí que se ponen en juego tanto los límites como posibilidades por los cuales los sujetos establecieron una identificación en ese espacio considerado público y sobre todo, en la capacidad de intervenir sobre éste.

Ello implica volver a pensar las configuraciones discursivas que desde el Estado se dieron; pero sobre todo, analizar la emergencia de un sujeto trabajador que, desde las interpelaciones del peronismo, configuró sus modos de intervención en lo público. Entonces, afirmar la porosidad entre ambas esferas, nos permite pensar una articulación de lógicas un poco más compleja de la que en general se admite. A fin de escrutar este intersticio, a continuación se analizará la categoría de espacio público como un espacio de significación social.

\section{El espacio público como modo de escenificación de lo social}

En la construcción del espacio público se evidenciaron diversas formas en las que se trató lo público. Rabotnikof (2005) analiza la constitución de lo público en torno a tres variaciones, que le otorgan una significación heterogénea. En primer lugar, se retoma a lo público como lo de interés común a todos; es decir, lo concerniente a una comunidad y lo que emana de esta. En segundo lugar, supone a lo público como lo manifiesto y ostensible; es decir, la implicancia de ser sometido a comunicación y examen. Por último, como una síntesis de las percepciones anteriores, la autora resalta a lo público con un carácter sobre lo que es accesible para todos, abierto. Entonces, en este trabajo analizaremos la constitución del espacio público a partir de la construcción de lo público entendido como un espacio autónomo que emerge desde la sociedad; y por otro lado, lo público asociado a la gubernamentalidad estatal (Retamozo, 2006). Ello nos propiciará un marco de análisis, para advertir las posibilidades de pensar este espacio como un escenario de significación social.

La caracterización del espacio público como una estructura mediadora entre la sociedad y el Estado, enfatiza la integración societal como una manera de comunidad que se constituye a partir de un conjunto de instituciones. Desde esta óptica, Rabotnikof (1995) supone que el espacio público es un ámbito de visibilidad de los individuos, que se integran en el momento 
ciudadano. En esto, referenciamos a Arendt (1998), al contener en su propuesta, la idea que frente a lo privado moderno -en su función de proteger lo íntimo de cada individuo- se descubrió como su opuesto no la esfera política, sino la esfera social. Por tanto, las esferas pública y privada contemplan una hibridación en lo social, dado que la primera se conformó en una función privada y la segunda ha pasado a ser el interés común existente.

En otro sentido, el espacio público en relación a un orden jurídico, supone la plena vigencia del Estado y la presencia de derechos y garantías para la vida en comunidad. En esta lectura, se enfatiza sobre la previsibilidad de las relaciones privadas y las interacciones en general, por lo que se recurre a instancias legales para su normal desarrollo. Este énfasis otorgado a la instauración suprema del derecho como el ámbito de lo público, implica una separación decisiva entre el Estado y la sociedad. En ello, el procesamiento de las demandas de la sociedad civil en el Estado se convierte en un filtro de racionalidad pública que otorga legitimidad a ese orden legal. La publicidad es central en este esquema, dado que es entendida como accesibilidad y control de los actos de quien detenta el poder (Rabotnikof, 1995). En estos términos, Habermas (1989) supone por esfera pública al dominio de la vida social en el que surge la opinión pública. La conformación de la esfera pública viene dado entonces por ciudadanos que poseen la posibilidad de participar y hacer pública sus expresiones privadas en relación a otros. De ahí que el poder coercitivo del Estado no es parte de la esfera pública, sino más bien su contraparte.

En todo caso, el espacio público constituido por un lado como representación de lo social y como el ámbito de la racionalización del poder por el otro, suponen especificaciones prescriptivas acerca de lo que se constituye como lo público, sin considerar sus condiciones de emergencia. Entonces, lo público se convierte a un nivel normativo, según Rabotnikof, enla alternativa entre el aseguramiento de los intereses privados y la participación activa de la ciudadanía en los asuntos comunes de la sociedad en su conjunto.

Ahora bien, es nuestro interés analizar al espacio público desde una visión que no sólo evite pensar sus componentes en términos dicotómicos, sino que también nos permita recrear el entremedio entre Estado y ciudadanía. De este modo, como todo orden social nunca se efectiviza desde una posición neutra, Groppo (2011) afirma que su construcción contiene la presunción de lazos y prescripciones en la conformación de dicho orden. De este modo, Laclau y Mouffe (1987) admiten la imposibilidad de clausura a toda identificación y que no puede estar determinada por sustancialidad alguna. Ello se vincula al establecimiento de un límite que se constituye a partir de un exterior constitutivo, por el cual la identidad es negada pero a su vez, es parte. En este punto, una posición discursiva de lo social habilita pensar la subversión de un orden social que se pretende definido de una vez y para siempre. El espacio público constituye 
el momento en que se despliega el carácter dinámico e inestable de las significaciones sociales. A su vez, se considera como el lugar en el que se reconocen diferentes puntos de identificación. A pesar de la disímil composición de un orden social, afirmamos que sus elementos (y momentos) son susceptibles de ser articulados (Laclau y Mouffe, 1987).

El espacio público adquiere un estatus determinado al especificarse como el momento en el que los diversos intereses confluyen, se articulan y se antagonizan. Por ello, Mauro (2010) afirma que en el espacio público “(...) puede jugarse la hegemonía, en tanto la tradición es objeto de una pugna hermenéutica por su apropiación y anclaje semántico, y el público es hipotéticamente y siempre (desigualmente) susceptible de articulación" (170). Desde esta perspectiva, se plantea la posibilidad de pensar el espacio público desde un carácter discursivo, en tanto hacemos evidente la imposibilidad fundante de los objetos sociales en una única esencia a priori. Por ello, podemos enunciar la configuración discursiva del espacio público como un objeto imposible, dado por su incapacidad de constituirse como un orden definitivo; y a su vez, se configura como un objeto necesario, por la posibilidad misma de ser alcanzado por algún orden particular (Laclau y Mouffe, 1987).

En esto, se fortalece el anudamiento entre el aspecto social y el aspecto íntimo de las identificaciones, como una co-constitutividad que viene a dar cuenta de la indecibilidad por la cual los sujetos se sostienen. El espacio público deviene en una parcialidad, en tanto supone la delimitación constante de sus términos y de los sentidos que lo circundan. Afirmamos pues, que no es posible pensar una separación entre los aspectos comunes e íntimos de una experiencia política, dado que ambos se encuentran vinculados en una relación de sobredeterminación, posibilitada por la incompletitud de toda estructura de significación (Morales y Reynares, 2010). El espacio público es un efecto de disputas hegemónicas, dado que la lucha por la representación inacabada de lo simbólico le otorga una pauta de dinamismo, imposible de simbolizar. Entonces, todo intento de clausurar un modo de orden se configura en una estructura indecidible y que, por efecto de una dislocación, recibe de manera hegemónica un nombramiento que se construye de manera universal (Groppo, 2011).

En estas consideraciones, la dicotomía entre espacio público y espacio privado queda atrás, para pensarlos más bien como lógicas tendientes a la articulación y constitutivos de lo político. El espacio público, como condición de lo político, es el lugar donde confluyen los aspectos diversos de los sujetos en un momento de lo común; por lo tanto, el orden de la disposición de lugares está en permanente exposición de ser tensionado de manera conflictiva. Por ello, como asumen Morales y Reynares (2010), será política cualquier interrupción que cuestione la delimitación de esas fronteras. Esto último expresa un límite, que constituye el espacio público a partir de lo que incluye o excluye. En este aspecto, la recuperación del antagonismo pone en 
evidencia el carácter precario del establecimiento de las fronteras de aquello que se considera como parte de lo público. Es decir, el antagonismo da cuenta de la contingencia que atraviesa la lucha por la identificación en un lugar común, para hacer visible aquello que se supone es parte de un ámbito íntimo. Entonces, automatizar el dominio de lo estatal en lo público; o bien, considerar al espacio público como un ámbito autónomo que emerge de la sociedad, implican reduccionismos analíticos de los cuales tenemos que hacernos eco. De este modo, nos desplazamos hacia una noción de espacio público como espacio de permanente conflicto, en donde se observa una disputa hegemónica por su contenido y su significado.

En función de lo desarrollado, interesa detenernos en dos aspectos para analizar la configuración del espacio público en el primer peronismo: por un lado, el carácter conflictivo de los símbolos recreados desde el Estado; y por el otro, los mecanismos de enunciación subjetiva que tal proliferación de sentidos suscitaron desde sectores mayoritarios de la sociedad. Ambas ideas nos otorgan la posibilidad de pensar los intersticios por los cuales los trabajadores fueron partícipes de la trama política, conformándose como sujetos enunciadores de demandas frente al actor estatal. Es decir, nos detendremos a analizar el carácter disruptivo de los actores sociales en lo público, asumiendo la apropiación de la discursividad de la experiencia política del peronismo.

\section{La escritura de la carta: ¿quién(es) escribe(n)?}

En tanto la revisión precedente nos otorgó un marco de discusión para analizar la constitución del espacio público durante el primer peronismo, nuestra mirada se direcciona a recuperar aquellas intervenciones de los sujetos hacia lo público, que pusieron en discusión los alcances de este espacio. Nuestro punto de partida implica retomar un corpus documental poco explorado, como el acervo de cartas y solicitudes enviadas a Juan y Eva Perón. Un trabajo acerca del análisis de la práctica epistolar en la esfera pública, es el de Fitzpatrick (1996). La autora, analizando las cartas enviadas durante la Rusia Soviética, sostiene una definición sobre las cartas enviadas a figuras de autoridad, en tanto los solicitantes realizaban peticiones de índole privada; mientas que los ciudadanos sostenían demandas de incidencia en el ámbito público. De este modo, Fitzpatrick afirma que las cartas de ciudadanos apelaban a modos de intervención de un orden "público", para establecer opiniones, sugerencias o denuncias. Por lo tanto, la consideración del ciudadano se establecía en tanto se apelaba en las cartas a un lenguaje de derechos y a sentidos sobre el bien común. 
A pesar de estas consideraciones, las implicancias de un sujeto dividido entre un ámbito privado y uno público sostendría, una vez más, un presupuesto de separación racional entre una y otra esfera de actuación. Esto constituye cierto estancamiento analítico en Fitzpatrick al aludir la emergencia de un ciudadano solo en sus intervenciones colectivas, sin encontrarse interpelado por sus posiciones íntimas. En este sentido, suponemos una característica relacional en la conformación de los sujetos sociales y que tanto su acepción íntima como pública, adquieren relevancia en los procesos de subjetivación. Para Laclau y Mouffe (1987), la plenitud de los sujetos se plantea bajo el deseo de clausurar su identidad. La figura del sujeto como tal, se encuentra penetrada por el mismo carácter polisémico, ambiguo e incompleto que la sobredetermina. Por lo tanto, el momento de clausura de una totalidad discursiva será siempre en diferido; entendiendo por ello que el momento de la emergencia de una subjetividad justamente se encuentra atravesado por una precariedad constitutiva de los actores sociales. Dado el deseo permanente de plenitud de los sujetos, Laclau y Mouffe afirman que ninguna de las posiciones de sujeto logra condensarse como posición separada, por lo que se introduce un horizonte entre esas posiciones de sujeto, como una totalidad imposible.

De este modo, en la escritura epistolar encontramos rastros de esas diversas posiciones subjetivas, a partir de la interpelación del peronismo que actuó como un registro de inteligibilidad para nuevas demandas. En ello, las cartas representan el comienzo de lo que las personas percibieron como una vía para entablar una comunicación con el Presidente que no fuera a través de los canales institucionales tradicionales, como el partido político o los sindicatos (Guy, 2017). Entonces, detenernos en este tipo de fuentes implica sostener una decisión en torno a la recreación del lazo identificatorio entre los sujetos y el peronismo. De ahí, se destaca la proliferación de solicitudes enviadas en torno a distintos aspectos cotidianos de los sujetos, en formato de demandas. Suponiendo ello una oportunidad de hacer llegar a las altas esferas del poder petitorios, con la expectativa de que iban a ser leídos (Acha, 2004). El análisis sobre la práctica epistolar nos lleva a cuestionar el carácter individual sobre el cual se cimentó la construcción de esas identificaciones. Desde el desarrollo de una práctica epistolar, se evidencia la emergencia de los sujetos, operando en esta práctica los ecos del contexto en una discursividad disponible que fue operando en esa misma significación. Esto último, abre paso a la idea que esa misma práctica se fue constituyendo a través de un diálogo con otros y que la forma epistolar justamente fue un modo de establecer relacionalmente, sus propias imágenes como sujetos enunciadores de demandas (Dobson, 2009) (3).

Nuestra apuesta pasa por problematizar la constitución del espacio público durante el primer peronismo. De este modo, los extractos de cartas elegidassuponen una intención de analizar los modos de intervención en lo público, en los cuales se instituye un sujeto social. De este 
modo, no nos basamos en un criterio de exhaustividad; sino más bien, en tomar imágenes sobre los modos en que la experiencia política del peronismo interpeló a determinados sujetos, que se consideraban excluidos del sistema socio-productivo. Por ello, aceptar la premisa de la problematización, implica alejarnos de todo criterio de exhaustividad, para avanzar en el análisis de los intersticios relacionales y la articulación subjetiva de actores (Glynos y Howarth, 2007). De esta manera, la problematización se constituye en una posibilidad de acceder a los modos en que adquiere inteligibilidad las intervenciones subjetivas, en un nuevo orden de lo considerado como lo público.

La carta, en este sentido, se constituye en una fuente heterogénea que otorga la posibilidad de analizar los intersticios en los cuales el sujeto recorre procesos (des)identificatorios. A su vez, la carta refleja los entramados sociales en la tensión siempre irresoluble de gestarse como un sujeto completo. Por ello, como señalan Barros, Morales, Reynares y Vargas (2016), el uso de la carta implica desmarcar de esta fuente novedosa, la posibilidad de acceder a una verdad última de sujeto. En esto, no sólo se pone en juego en el análisis la palabra escrita, sino también la posibilidad de pensar las condiciones subjetivas por las cuales se recrea este diálogo con otro. A su vez, en la carta se percibe la indecidibilidad en la cual el sujeto se constituye. Por lo tanto, quien escribe la carta se inscribe en la precariedad del lenguaje, como también en los modos de enunciación disponibles (Barros et al., 2016). A continuación, procederemos a recuperar algunos extractos de misivas, para advertir el encuentro entre las disponibilidades discursivas de los escritores de cartas y sus modos de intervención en el espacio público.

\section{El sujeto en la carta: la irrupción en lo público}

En este apartado, retomaremos extractos de cartas para dar cuenta de la intervención de sujetos en el espacio público. En este ejercicio, especificaremos el lazo entre los sujetos y la disponibilidad de un registro discursivo, en términos de visibilización en lo público. Al rastrear una carta de un hombre de San Andrés, aparece en primer lugar, su colaboración con el movimiento peronista:

Pero sintiéndome demasiado modesto en el sentido de mi colaboración con el movimiento del Peronismo y más aún ante los innumerables sacrificios que hace V. E. y vuestra incansable Compañera; me tomo nuevamente la libertad de molestar vuestra atención como lo hice en su oportunidad en el llamado de la Isla Huemul, para ofrecer mi incondicional colaboración para servir la noble causa del peronismo, nada pido mi General: 
solo quiero servir a esa idea que reivindico a mi Argentina ante el mundo y la sacó del barro servil en que los incalificables políticos a sueldo de la oligarquía la había sumido (AGN, legajo 462).

En esta intervención, el sujeto explicita su total anuencia con el movimiento peronista y a su vez, en la colaboración, hace referencia al desinterés que lo lleva a ponerse a disposición. Manifestarse a partir de la marginalidad de los trabajadores, adquiere inteligibilidad en una lógica del servicio, en tanto quien escribe se ofrece para colaborar con el gobierno. De hecho, el peronismo es la oportunidad de sacar a quienes están en su misma condición en el barro servil. La lógica del servicio que propone el autor de la carta, tiene que ver con que servir al peronismo es servir a la Patria. De allí, toma impulso su pedido para ser tenido en cuenta en la obra de Perón, afirmando su ambición de ocupar un lugar de actividad, como se puede notar en el siguiente extracto:

Ruego a V. E. se sirva decir que lugar debo ocupar en este movimiento con el cual confraternizan mis ideas con las de V. E. y nuevamente puntualizo que nada pido ni ambiciono más que un lugar para colaborar desinteresadamente en la obra emprendida, la cual veo noble, sana y justicialista; cualquier tarea en bien del Peronismo me honrará por igual, así fuera la más humilde, siempre que sea para divulgar la doctrina peronista, entre mis connacionales que aún no quieren o no pueden comprender el enorme sentido patriótico que el peronismo lleva por alma (AGN, legajo 462).

En la demanda de ocupar un lugar en el movimiento peronista, se anuda la necesidad del sujeto de participar en el despliegue del Estado peronista. En este sentido, la demanda de intervenir en el espacio público se percibe en torno a un lugar dignificante, atribuyéndole a esa posición una caracterización de labor noble, sana y justicialista. A su vez, la demanda parece no poseer un parámetro instrumental; más bien implica una identificación, en la que el sujeto se constituye a sí mismo a partir de esa afectividad y ese auto reconocimiento como trabajador. Las intervenciones en las cartas expresan cierto grado de conflictividad social. La lectura que los mismos sujetos hicieron de su propia realidad, nos muestra la enunciación de respuestas a sus problemáticas cotidianas. Asimismo, nos permite enfatizar la dimensión política de las peticiones, en la medida en que allí se disputan los límites del orden social, entendido desde un carácter excluyente. En este caso, recuperamos una carta de un docente rosarino, en la cual interviene en la resolución de problemas creando un Departamento de Soluciones Populares: 
Lorenzo Lazarte, argentino, peronista y leal admirador de su fornida personalidad, se complace en saludarle con su más alta distinción y se permite molestar su atención para hacerle llegar su modesta colaboración, en algunas iniciativas, como asi también reiterarle su disposición para ponerse a su servicio (AGN, legajo 474).

Más adelante, Lazarte continúa:

Si fuera intendente consultaría al pueblo para saber cuales son sus necesidades y sus aspiraciones y luego seguiría el magistral desarrollo del 2ํo plan Quinquenal; crearía una Dirección de Planificación de Trabajos Municipales, para que se proceda a su estudio y se contemplen las posibilidades de solución, etc. Crearía un Departamento de Soluciones Populares, consultando al pueblo con este interrogante. Cómo solucionaría Ud. este problema? (AGN, legajo 474).

En esta carta, es notable la circulación discursiva del Segundo Plan Quinquenal. El autor baja a su realidad local una propuesta similar, en tanto visualizándose como Intendente podría llegar a proponer un plan como el estipulado a nivel nacional. En ello, resuena la conexión entre problemas específicos locales y las soluciones que se dieron en el ámbito nacional (Elena, 2005). Más allá de los planteos presentados (en muchos casos, la disparidad de ideas se reflejaba en la imposibilidad práctica de su realización), nos anclamos en las maneras de hacer audible los conflictos que los sujetos proponían. En este sentido, la consigna “¿Cómo solucionaría Ud. este problema?" es una manera de expresar el significado que tuvo la campaña por el Segundo Plan Quinquenal. Es decir, se percibe un efecto de realidad (Dobson, 2009), dado que el pedido de creación de una institución específica implica un diálogo entre el contexto operando en la carta. A su vez, a un nivel subjetivo, quien escribe propone soluciones desde su propio lugar de enunciación. La solución, en este caso, no es de cualquier tipo, sino que son soluciones populares. Estas soluciones abarcan a un todo más complejo que una simple demanda individual, por lo que la narrativa sobre lo popular significa la dimensión de reconocer un todo comunitario, que exige esa nueva institucionalidad.

Con la intención de mostrar la demarcación del espacio público como un escenario de identificación subjetiva, nos detenemos a analizar esa identificación desde sectores históricamente vulnerados. Al suponer la tensión de los límites de lo público, hacemos referencia a la emergencia de un nuevo sujeto. Este sujeto, por su condición histórica de vulnerado del sistema socio-productivo, se arroga a sí mismo la capacidad de dictaminar acerca de sus propios problemas y resoluciones, a partir de concepciones propias sobre lo que considera bueno. Por ello, Juan Ramón de Mendoza escribe: 
Al decir que soy un primer descamisado en Mendoza, lo digo por pura verdad (...). General, yo soy pobre, notablemente pobre y las ambiciones de los políticos se han despertado en forma terrible; pero ello no significa que me sienta derrotado, todo lo contrario, estoy moralmente satisfecho y me permito felicitarlo porque con hombres como nosotros, podrá llegar sin dificultad a alguna meta (AGN, legajo 462).

En esta carta, llama particularmente la atención la posición de enunciación de quien la suscribe: él es pobre. La emergencia de un sujeto trabajador da cuenta del paso de alguien que no era reconocido a poseer derechos; pero también de posicionarse como parte legítima del orden social del cual fueron excluidos. En esta carta, el nombramiento de su persona como un primer descamisado, lleva al escritor a ponerse en el lado de la exclusión y al expresarse como notablemente pobre, sigue sosteniéndose en esa posición social. Pero ello no lo desanima, se afirma como moralmente satisfecho porque justamente ser pobre durante el peronismo supuso una virtud.

Con esto, se puede afirmar el desencadenamiento de una subversión del concepto mismo sobre la pobreza. La situación de marginación es vista como lo bueno, porque ello significa el sacrificio diario del trabajo. A su vez, esa condición de pobre habilita a quien escribe, no solo de pasar a ser un privilegiado en el espacio social; sino que además asegura con firmeza que personas pobres como él, son el motor de la transformación de la Nación. De este modo, quien escribe, aprovecha su particular experiencia para poner un nombre a la comunidad y sobre quiénes son los verdaderos atribuidos a ser parte de esta.

Desde otro tipo de conflictividades, se aborda la intervención de los sujetos en el espacio público, trayendo a colación una carta que especifica el rol de la justicia. Por ello, recuperamos el siguiente extracto, que nos resulta esclarecedor:

Lorenzo Monsó Mensegué, argentino, de edad 46 años, respondiendo al llamado del Excelentisimo Señor Presidente General Juan D. Perón, pasa a exponer lo siguiente: En la era del Justicialismo, no puede seguir empleándose los mismos procedimientos, que en la era de la oligarquía. Los actuales códigos de procedimientos para la aplicación de la Justicia, considero que no están de acuerdo con el Justicialismo peronista, estos, son sumamente lentos, costosos y perjudiciales para el pueblo (AGN, legajo 445).

En esta instancia, el sujeto que escribe la carta identifica aquel daño de la era de la oligarquía y su persistencia en el régimen peronista. A su vez, identifica esa demanda como una necesidad del pueblo y habla por ese pueblo que sigue siendo dañado por una justicia lenta, costosa y 
aproximamos, corrupta. Allí es donde la necesidad del autor de la carta se traduce en demanda; es decir, el conflicto modela la formulación de esta demanda en relación a un adversario que se constituye como el que lo ha privado de ese derecho. Entonces, en esta alocución, la denuncia intenta tensar ese régimen peronista, en tanto se supone que en la era del Justicialismo, en donde impera una acción reivindicativa de los excluidos, todavía existen mecanismos que perjudican a ese mismo pueblo, como la justicia.

Es notable la constante apelación a la división del espacio social, como el modo de articular las demandas del pueblo. La separación en dos de la sociedad fue necesaria como un modo de hacer inteligible soluciones al respecto de la persistencia de situaciones de exclusión. De hecho, la percepción en torno a la democratización social presuponía la persistencia del conflicto social, contraponiendo imágenes sociales en torno a la oligarquía egoísta y el pueblo sano y virtuoso; descamisados en su sentido peyorativo, pero también como lo positivo de esa sociedad que se encontraba escindida (Romero, 2014).

A la denuncia sobre la persistencia de una justicia oligárquica, Mensegué le suma la propuesta de la creación de una nueva institución que dé cuenta de esa necesidad conflictuante para la mayoría, como se muestra a continuación:

\begin{abstract}
Mi sugerencia es la de crear un Tribunal del Pueblo, que tenga por finalidad determinar con el mínimum de tiempo, de 15 a 20 días, si es culpable ó no, a prima face, o si se debe o no la suma que se reclame.

Dicho Tribunal, podría dictar fallos, inducir a actos conciliatorios ó pasar los correspondientes sumarios a Juez competente con sus correspondientes observaciones. En los casos de demanda por sumas de dinero, podría autorizarse dicha demanda, con papel simple y sin pagar el llamado derecho de justicia, y cuya reposición del sellado correspondiente, podría efectuarse después del fallo y por quien corresponda (AGN, legajo 445).
\end{abstract}

La creación del Tribunal del Pueblo vendría a constituir el modo de rectificación de esa justicia que no sirve al pueblo y que no está constituida para este; siendo el principal argumento una justicia lenta y costosa, a la cual el mismo pueblo no puede acceder. En suma, la carta propicia un espacio en el cual se tensionan los límites del régimen mismo, en tanto el peronismo redefinió la sociedad civil, restringiendo los espacios habilitados para algunos actores o bien, la redefinición del rol de instituciones ya establecidas (Elena, 2005). Hacernos eco de aquellas intervenciones que se abordan en forma de denuncia y sin demasiadas adulaciones, nos ayuda a recuperar las limitaciones del mismo régimen peronista y a su vez, de las posibilidades arrogadas de los sujetos mismos de poder enunciar en palabras (escritas) esa limitante. 
En las cartas retomadas, encontramos una visibilización de aquellas experiencias conflictuantes de la vida de los sujetos. Allí, es notoria la recuperación de las palabras de Perón para hacerlas justificativos frente a la conflictividad y exclusión social. Entonces, los sujetos que se dejan leer en las cartas, se convocan a sí mismos en un momento en el cual una forma de hacer presente su daño es exigir presencia en esa representación; porque del otro lado de lo irrepresentado, solo hay exclusión. A su vez, en estas intervenciones a través de la escritura de cartas, hay una persistencia por el nombramiento de lo público. Es decir, hay una persistencia por otorgarle significaciones a esas expresiones que son parte de lo común y que en variados casos, representan las motivaciones particulares de sectores trabajadores, que se enuncian como un momento de universalidad.

\section{Comentarios finales}

Recuperando los objetivos propuestos de analizar por un lado la especificación del espacio público como un escenario de identificación subjetiva; y, por otro lado, mostrar aquellas intervenciones de los sujetos en el espacio público durante el primer peronismo, hacemos eco de pensar ese espacio como la constitución de un orden de lo común, delimitado por la conflictividad social. El carácter de la intervención de los sujetos en lo público implicó aquellos lazos afectivos y carismáticos (Guy, 2017) que fueron entretejiendo la experiencia política del peronismo, con la emergencia de una subjetividad colectiva en torno a sectores trabajadores. Por otra parte, el espacio público intervenido nos convoca a pensar en aquellos desbordes que el peronismo supuso frente a las demandas de los actores sociales. Por ello, retomamos aquellas cartas en los cuales se visualizan las limitaciones del régimen peronista y hacen eco de esas mismas posibilidades discursivas para elucubrar y organizar posibles soluciones. De este modo, afirmamos que los sujetos se convocan a sí mismos a partir de la presencia del daño y por el cual, demandan nuevos modos de institucionalización y de tomar parte en esa representación.

Pensar la categoría de espacio público, con la intención de deconstruir sus significaciones entre la idea de una mediación en la sociedad civil y como régimen del control de la ley, nos otorga una pista para sugerir su constitución contingente y precaria. Asumiendo de esta manera, el desafío de establecerlo como el momento de lo político, en el cual se desarrolla el carácter inestable y precario de las relaciones sociales. Entonces, la recuperación de estos extractos de cartas nos dicen un poco más sobre la conformación de un nuevo espacio de intervención. $\mathrm{Y}$ que, en todo caso, nos muestran las ambivalencias constitutivas de un sujeto 
que además de reconocerse como peronista, se ponía en un lugar de privilegio para establecer un diálogo con el actor estatal y demandar, en un nuevo espacio de actuación. De este modo, apelamos a reconstruir desde la práctica epistolar, las especificidades de la intervención en el espacio público durante el primer peronismo, inscribiéndolo como un espacio de encuentro, de disputa, de consenso y también de construcción de hegemonía (Retamozo, 2006). Entonces, la constitución de un nuevo espacio público expresa, en cierto modo, los espacios relaciones entre sujetos y sus modos de escenificar sus vivencias cotidianas, en un escenario político más amplio.

\section{Notas}

(1) La práctica epistolar encontró gran expresión a partir de la campaña "Perón quiere saber lo que su pueblo necesita", en diciembre de 1951, en el marco de la concreción del Segundo Plan Quinquenal. Este extenso corpus, compuesto por miles de iniciativas, se encuentra dispuesto en legajos y cada carta constituye una iniciativa, la cual posee una carátula identificatoria con número de iniciativa, iniciador, área de injerencia, resumen de la carta y lugar.

(2) Trabajos que retoman el análisis del espacio público, como el de Ballent (1997) que referencia la dimensión arquitectónica del uso popular del espacio público que dominó durante el primer peronismo; o bien el de Carro (2008) acerca de las prácticas sociales en el primer peronismo que supusieron maneras de ocupar y delimitar el espacio público, nos hablan sobre los diversos modos de nombrar esta categoría en relación al peronismo.

(3) Elena (2005) señala que en las cartas remitidas a figuras estatales no se descarta la asimetría de poder existente entre el Estado y los sujetos, por lo que se intenta recuperar la politicidad del discurso peronista en relación a una nueva subjetividad que corroe los límites mismos de la comunidad.

\section{Bibliografía}

Acha, O. (2004). Sociedad civil y sociedad política durante el primer peronismo. Desarrollo Económico, 44(174), julio-septiembre, pp. 199-230.

Acha, O. (2016). Lo público en la hegemonía: análisis categorial de un concepto para el estudio del peronismo. Actas del V Congreso de Estudios Sobre el Peronismo 1943-2016, Universidad Nacional del Noreste.

Archivo General de la Nación (AGN). Fondo documental Secretaría Técnica Primera y Segunda Presidencia del Teniente General Juan Domingo Perón (1946-1955) (Legajos 445, 462, 474 y 462). Recuperado de http://agnargentina.gob.ar/indices/secretaria_de_Peron.pdf Arendt, H. (2003). La esfera pública y la esfera privada. En Arendt, H. La condición humana (cap. 2). Buenos Aires: Paidós. 
Ballent, A. (1997). Las huellas de la política. Arquitectura, vivienda y ciudad en las propuestas del Peronismo. Buenos Aires, 1945-1955. (Tesis doctoral). Doctorado en Historia, Facultad de Filosofía y Letras, UBA. Recuperado de https://bit.ly/2PGnnMS

Barros, M.; Morales, V.; Reynares, J. M. y Vargas, M. (2016). Las huellas de un sujeto en las cartas a Perón: entre las fuentes y la interpretación del Primer Peronismo. Revista Electrónica de Fuentes y Archivos, 7(7), Córdoba, pp. 234-260.

Carro, J. P. (2008). El mundo peronista a través del noticiero cinematográfico. Sucesos Argentinos (1946-1952). Signo y Pensamiento, XXVII, julio-diciembre, pp. 203-212.

Castillo, F. (2012). Lo consagratorio y lo venerable: la "peronización" del espacio público en San Salvador de Jujuy. Pilquen, XIV(15).

Dobson, M. (2009). Letters. En Dobson, M. y Ziemann, B. (editores). Reading Primary Sources. The interpretation of texts from 19th and 20th century history (cap. 3). UK: Routledge.

Elena, E. (2005). What the People Want: State Planning and Political Participation in Peronist Argentina, 1946-1955. UK: Cambridge University Press.

Fitzpatrick, S. (1996). Supplicants and Citizens: Public Letter-Writing in Soviet Russia in the 1930s. Slavic Review, 55(1), primavera, pp. 78-105.

Glynos, J. y Howarth, D. (2007). Logics of critical explanation in social and political theory. UK: Routledge.

Groppo, A. (2011). Tres versiones contemporáneas de la comunidad: Hacia una teoría política post-fundacionalista. Revista de Filosofía y Teoría Política, 42, Universidad Nacional de La Pampa, pp. 49-68.

Guy, D. (2017). La construcción del carisma peronista. Cartas a Juan y Eva Perón. Colección Ciudadanía e Inclusión. Buenos Aires: Biblos.

Habermas, J. (1989). The publicsphere. En Seidman, S. (edit.). Jurgen Habermas society and politics. Boston: Beacon Press.

Laclau, E. y Mouffe, C. (1987). Hegemonía y estrategia socialista. Buenos Aires: FCE.

Mauro, S. (2010). El espacio público y los significantes sociales. Democracia y escenificación del antagonismo. Convergencia, 54, septiembre-diciembre, UAEM, México, pp. 161174.

Morales, V. y Reynares, J. M. (2010). La política y el espacio público. Constitución discursiva y potencial emancipatorio. Pensamiento Plural, julio-diciembre, 2010, pp. 77-90.

Plotkin, M. (1994). Mañana es San Perón. Propaganda, rituales políticos y educación en el régimen peronista (1946-1955). Buenos Aires: Ariel Editorial.

Rabotnikof, N. (1995). El espacio público: variaciones en torno a un concepto. En Rabotnikof, N.; Velazco, A. e Iturbe, C. (Comps.). La tenacidad de la política. México: UNAM-IIF. 
Rabotnikof, N. (2005). En busca de un lugar común. El espacio público en la teoría política contemporánea. México: Universidad Nacional Autónoma de México/Instituto de Investigaciones Filosóficas.

Retamozo, M. (2006). Notas en torno a la dicotomía público-privado: una perspectiva política. Reflexión política, 8(16), diciembre, Universidad Autónoma de Bucaramanga, Colombia, pp. 26-35.

Romero, L. A. (2014). Sociedad democrática y política nacional y popular: la Argentina en la primera mitad del siglo XX. Estudios Sociales, 46, primer semestre, pp. 145-170.

Torre, J. C. y Pastoriza, E. (2004). La democratización del bienestar. En Torre, J. C. Nueva Historia Argentina (Tomo VIII). Argentina: Editorial Sudamericana. 